\title{
Study of acceptance of post-abortal contraception in a tertiary care centre
}

\author{
Indumathi H. K., Shashikala B. Patil*, Radhika, Savitha C., Nayana M. S.
}

Department of Obstetrics and Gynecology, BMCRI, Bangalore, India

Received: 20 July 2021

Accepted: 10 August 2021

\section{*Correspondence:}

Dr. Shashikala B. Patil,

E-mail: drshashika@gmail.com

Copyright: (c) the author(s), publisher and licensee Medip Academy. This is an open-access article distributed under the terms of the Creative Commons Attribution Non-Commercial License, which permits unrestricted non-commercial use, distribution, and reproduction in any medium, provided the original work is properly cited.

\section{ABSTRACT}

Background: Unsafe abortions is causing about $8 \%$ of maternal deaths in India. So, it's important to use contraception not only for spacing but also to prevent unintended pregnancies. It is well known that fertility is resumed in the immediate cycle following an abortion. Post abortal contraception is very important in preventing pregnancies in the immediate post-abortal period. This study was intended to know the acceptance of post-abortal contraception in women coming for medical termination of pregnancy (MTP) or following spontaneous abortion in tertiary care centre. Thus, it is vital to know the choices made by them, to know the method accepted so that it will be helpful in bringing awareness in those who do not opt for post-abortal contraception. Aims and objectives were to study the acceptance rate of postabortal contraception. Also, to study the method of contraception accepted.

Methods: It was a retrospective cohort study from 2018 to 2020 done in Vani Vilas hospital, BMCRI, a tertiary hospital. A total of 2273 patients were enrolled in the study. Data was collected from both 1 st trimester and $2^{\text {nd }}$ trimester abortion patients (spontaneous/induced) from the Comprehensive abortion care register. The acceptance and method of contraception accepted was studied. Inclusion criteria were-women coming to tertiary centre for abortion (spontaneous/induced) to Vani Vilas hospital. Exclusion criteria were-Molar pregnancy and Ectopic pregnancy. Demography, educational status, details of spontaneous or induced abortions, parity and gestational age at abortion, the acceptance and methods of contraception accepted were studied.

Results: A total of 2273 patients were included in the study of which 738 were MTP and 1535 were cases of spontaneous abortion. $912(40.12 \%)$ were primigravidae and $1361(59.87 \%)$ were multigravida. Various methods of contraceptives were accepted by $1973(86.80 \%)$ patients, whereas 300 (13.19\%) did not opt for any method of contraception. Of 1973 patients, 176 (7.7\%) underwent sterilization.

Conclusions: The acceptance rate of post-abortion contraceptive methods was good. Acceptance of COCs and LARC was almost similar in this study. Immediate acceptance of contraception in the post-abortal period is very crucial in reducing unintended pregnancies and abortions hence family planning services after abortion need to be strengthened.

Keywords: Post abortal, Contraception, IUCD, Family planning

\section{INTRODUCTION}

Amidst growing population, prevalence of abortion is also on rising toll. According to WHO, every year in the world there are an estimated 40-50 million abortions. This corresponds to approximately 125,000 abortions per day.

We also come across increasing unintended pregnancies and teenage pregnancies. It is still not uncommon to see
MTP pill abuse and illegal abortions. Maternal mortality due to unsafe abortions in our country is still about $8 \%$, which is unacceptable. Mortality due to unsafe abortions is easily preventable. Not only providing safe abortion services with optimum standards is important, promotion of family planning services is equally vital. Promoting the use of contraceptive methods to prevent unwanted pregnancies is one of the most effective strategies to 
reduce abortion rates and maternal morbidity and mortality. ${ }^{1}$

Its high time the awareness about contraception become more effective in India. Still hindrance prevails for acceptance or usage of contraception in India, which could be due to lack of counseling, illiteracy, poverty, strong religious beliefs, misconceptions or difficult access to healthcare facilities. ${ }^{2}$ All these things also contribute to discontinuation or failure of contraception. All the more post-abortal contraception should be given more importance by health care centres, as strengthening the resources and bringing people to accept contraception in immediate post abortal period is important. The first ovulation may take place as soon as 2 weeks after abortion and half of the women may ovulate by 3 weeks. Hence commencement of effective contraception is necessary even before the first post-abortal menstrual period. Also, women are highly motivated as regards to contraception at this time. ${ }^{3}$ Majority of these women do not want to become pregnant again in the near future. WHO also recommends spacing of at least 6 months between abortion and next pregnancy. Therefore, providing family planning services as a part of postabortion care can improve contraceptive acceptance and help break the cycle of repeated unwanted pregnancies. Providing it in the same facility increases acceptance. The intent of this study was to know the acceptance of post-abortal contraception and the method chosen in this tertiary centre.

\section{METHODS}

This was a retrospective cohort study from July 2018 to June 2020 done in the department of obstetrics and gynecology, Vani Vilas hospital, BMCRI, a tertiary care center. Women coming to tertiary centre for abortion (spontaneous/induced) were included in the study. A total of 2273 patients' data was collected. 738 patients sought MTP in this institute and 1535 patients came with spontaneous abortion. Among women with spontaneous abortion some had complete abortion and the rest came with inevitable or incomplete abortion. Those with complete abortion required no intervention. Medical or surgical or both methods were used in cases of MTP. Whereas patients with incomplete abortion underwent procedures like MVA (Manual vaccum aspiration) or EVA (Electric vaccum aspiration). Molar pregnancy and ectopic pregnancy were excluded from the study. All patients will be prior counseled regarding the procedure and complications, detailed information about the need and methods available for post-abortal contraception was explained. Counseling was done by health care workers who are well trained in Comprehensive abortion care services. Motivation to accept a contraception of choice was a priority.

The data was collected from the comprehensive abortion registers and entered in the proforma after hospital ethical committee approval. The data collected was analyzed.
Statistical analysis data management and analysis was done with appropriate statistical tests using SPSS software.

\section{RESULTS}

In this study there were a total of 2273 patients. Table 1 depicts age wise distribution of cases. Majority were in the age group 20-24 years i.e., 898 (39.5\%). Less than 19 years constituted $159(6.99 \%), 846(37.21 \%)$ between 25 30 years and $370(16.27 \%)$ were above 30 years of age.

Women belonging to different religions represent our study population. Hindus were 1405 (61.81\%), Muslims were $580(25.51 \%), 265(11.65 \%)$ where Christian's others constitute a small number of $23(1.01 \%)$ (Table 2$)$.

Table 1: Age group wise distribution of cases.

\begin{tabular}{|lll|}
\hline Age (Years) & $\begin{array}{l}\text { Number, } \\
(\mathbf{n = 2 2 7 3})\end{array}$ & Percentage $(\%)$ \\
\hline $\mathbf{1 0}$ & 159 & 6.99 \\
\hline $\mathbf{2 0 - 2 4}$ & 898 & 39.5 \\
\hline $\mathbf{2 5 - 3 0}$ & 846 & 37.21 \\
\hline $\mathbf{3 0}$ & 370 & 16.27 \\
\hline
\end{tabular}

Table 2: Distribution according to religion.

\begin{tabular}{|lll|}
\hline Religions & $\begin{array}{l}\text { Number, } \\
(\mathbf{n = 2 2 7 3 )}\end{array}$ & Percentage $(\%)$ \\
\hline Hindu & 1405 & 61.81 \\
\hline Muslim & 580 & 25.51 \\
\hline Christian & 265 & 11.65 \\
\hline Others & 23 & 1.01 \\
\hline
\end{tabular}

The 402 (17.68\%) patients had no formal education, whereas $1009(44.39 \%)$ had primary education and 862 (37.92\%) had secondary education as depicted in Table 3.

Table 3: Educational status of the beneficiaries.

\begin{tabular}{|lll|}
\hline $\begin{array}{l}\text { Educational } \\
\text { status }\end{array}$ & $\begin{array}{l}\text { Number, } \\
(\mathbf{n}=\mathbf{2 2 7 3})\end{array}$ & Percentage $(\%)$ \\
\hline $\begin{array}{l}\text { No formal } \\
\text { education }\end{array}$ & 402 & 17.68 \\
\hline $\begin{array}{l}\text { Primary } \\
\text { education }\end{array}$ & 1009 & 44.39 \\
\hline $\begin{array}{l}\text { Secondary } \\
\text { education }\end{array}$ & 862 & 37.92 \\
\hline
\end{tabular}

The $1453(63.92 \%)$ were in first trimester and 820 $(36.07 \%)$ in second trimester at the time of abortion as shown in Table 4. Primigravidae were 912 (40.12\%) and multigravida were about $1361(59.87 \%)$ as shown in Table 5. Table 6 shows induced (MTP) cases were 738 (32.46\%) and 1535 patients came with spontaneous abortion or incomplete abortion. Table 7 shows the methods adopted for abortions, manual vaccum aspiration was done in 1658 (72.94\%) and medical method of abortion was used in 481 $(21.16 \%)$ patients. Electric vaccum aspiration was done in 
10 patients $(0.43 \%) .101(4.44 \%)$ patients required no procedure as scan showed no evidence of retained products. $23(1.01 \%)$ patients required hysterotomy. Surgical method was resorted to in second trimester as the medical methods had failed or were contraindicated.

Table 4: Gestational age at abortion.

\begin{tabular}{|lll|}
\hline $\begin{array}{l}\text { Period of } \\
\text { gestation }\end{array}$ & Number & Percentage $(\%)$ \\
\hline First trimester & 1453 & 63.92 \\
\hline Second trimester & 820 & 36.07 \\
\hline
\end{tabular}

Table 5: Parity of the study group.

\begin{tabular}{|lll|}
\hline Parity & Number & Percentage (\%) \\
\hline Primigravida & 912 & 40.12 \\
\hline Multigravida & 1361 & 59.87 \\
\hline
\end{tabular}

Table 6: Distribution of induced and spontaneous abortion.

\begin{tabular}{|lll|}
\hline Type of abortion & Number & Percentage (\%) \\
\hline Induced & 738 & 32.46 \\
\hline Spontaneous & 1535 & 67.53 \\
\hline
\end{tabular}

Table 7: Methods.

\begin{tabular}{|lll|}
\hline Methods & Number & Percentage $(\%)$ \\
\hline MVA & 1658 & 72.94 \\
\hline MMA & 481 & 21.16 \\
\hline EVA & 10 & 0.43 \\
\hline $\begin{array}{l}\text { Surgical } \\
\text { (Hysterotomy) }\end{array}$ & 23 & 1.01 \\
\hline $\begin{array}{l}\text { No procedure } \\
\text { (complete } \\
\text { abortion) }\end{array}$ & 101 & 4.44 \\
\hline
\end{tabular}

Table 8: Family planning method accepted.

\begin{tabular}{|lll|}
\hline Methods & Number & Percentage (\%) \\
\hline PAIUCD & 348 & 15.31 \\
\hline COC & 672 & 29.56 \\
\hline $\begin{array}{l}\text { Injection } \\
\text { DMPA }\end{array}$ & 290 & 12.75 \\
\hline $\begin{array}{l}\text { Female } \\
\text { sterilization }\end{array}$ & 176 & 7.74 \\
\hline $\begin{array}{l}\text { Male } \\
\text { sterilization }\end{array}$ & 0 & 0 \\
\hline Male condoms & 487 & 21.42 \\
\hline No methods & 300 & 13.19 \\
\hline
\end{tabular}

All patients were counseled regarding methods of contraception suitable for them and complications associated with them. Table 8 depicts the rate of acceptance of different methods of contraception. Overall, $1973(86.80 \%)$ patients chose some method of contraception. $300(13.19 \%)$ patients did not use any method of contraception. Most chosen method of contraception was combined oral contraceptive pills i.e., $672(29.56 \%)$ followed by barrier methods (male condoms) i.e., $487(21.42 \%)$ clients. Long-acting reversible contraceptives (LARC) like PAIUCD insertion was done in $348(15.31 \%)$ and $290(12.75 \%)$ opted for Injection DMPA. Total acceptance of LARC was in $28.06 \%$ of our clients. $176(7.74 \%)$ underwent female sterilization. No couple were motivated to get male sterilization done.

\section{DISCUSSION}

From this study we wanted to know how far we were successful in meeting the contraception needs in postabortal women. Ours is a tertiary centre catering comprehensive abortion care service. Of 2273 post-aboratl patients, $1973(86.80 \%)$ chose some method of contraception. Most chosen method of contraception was combined oral contraceptive pills i.e., 672 (29.56\%) followed by barrier methods (male condoms) i.e., 487 $(21.42 \%)$ clients. Long-acting reversible contraceptives like PAIUCD insertion was done in 348(15.31\%) and 290 (12.75\%) opted for Injection DMPA. Preference for longacting contraception in post-abortal period was good. 176 (7.74\%) underwent female sterilization. 300 (13.19\%) patients did not use any method of contraception. None underwent male sterilization.

In a similar study done by Yogesh et al 400 women were studied for acceptance of post-abortal contraception, it was found that $64(16 \%)$ cases had barriers contraception (condom), $52(13 \%)$ cases had pills, $70(17.5 \%)$ cases had IUCD, $106(26.5 \%)$ cases had permanent method, 48 (12\%) cases had injectable contraception and 60 (15\%) had no method of contraception use. ${ }^{2}$ Acceptance of postabortal contraception was $85 \%$. Overall acceptance of contraception was comparable with our study though methods chosen varied.

In a study done by Ferreira et al $97.4 \%$ accepted the use of at least one contraceptive method. Half of the women chose injectables, while the second most chosen method was oral contraceptives $(33.6 \%)$, followed by condoms $(15.1 \%)$. Only one woman chose IUD. whereas in our study about $15 \%$ (348) of women accepted IUCD. Despite the availability and provision of all contraceptive methods, only four methods were accepted by the women in study done by Ferreira et al followed by counseling. The most popular methods were oral contraceptives and injectables, followed by condom and IUD. ${ }^{4}$ The present study also showed OC pills as most accepted method.

A systematic review and meta-analysis done by Bizuneh et al on post-abortion family planning use in Eastern Africa, a total of twenty-nine cross-sectional studies with 70,037 study participants were included. ${ }^{5}$ The overall pooled prevalence of post-abortion family planning utilization was $67.86 \%$ (95\% CI 63.59-72.12). The most widely utilized post-abortion family methods were injectable $33.23 \%$ (95\% CI 22.12-44.34), followed by 
implants $24.71 \% \quad(95 \%$ CI 13.5335 .89$)$ and oral contraceptive pills $23.42 \%$ (95\% CI 19.95-26.89). Usage of injection DMPA is less in our study compared to the above review.

In a study done by Kathpalia et al female sterilization was the commonest method of family planning (39.6\%) adopted by the couples and barrier contraception was the second (18.6\%). ${ }^{6}$ Acceptance of female sterilization is almost double compared to our study. Male sterilization was accepted by very few $(5.0 \%)$. None have come forward for male sterilization in our study.

Before the abortion procedure, we have to be certain that the woman's physical condition and emotional status is appropriate for counseling on contraception. Provider/counselor should respect her right to accept or refuse post abortion contraception. The service provider/counselor should consider both, the woman's clinical condition and personal situation and discuss any potential barriers to the successful adoption of contraception in a sensitive manner. Method Specific Counseling is certainly going to give good impact.

Methods chosen can differ if women have undergone spontaneous abortion as she might want to conceive in near future, whereas those undergoing MTP for unwanted pregnancies tend to opt for long-acting contraceptives or permanent sterilization.

\section{Limitations}

The limitations of the study are, it did not allow to investigate causal claims about the impact of counseling. There was no follow up to know whether or not they continued the use of the contraceptive method that they selected.

The data from the study reinforce the need to implement a women friendly counseling centres which should also include the spouse. Effective counseling and making family planning service accessible are complimentary in increasing the acceptance of post-abortal contraception.

\section{CONCLUSION}

The acceptance rate of post-abortion contraceptive methods was good. Acceptance of COCs and LARC was almost similar in this study. Immediate acceptance of contraception in the post-abortal period is very crucial in reducing unintended pregnancies and abortions hence family planning services after abortion need to be strengthened.

Funding: No funding sources

Conflict of interest: None declared

Ethical approval: The study was approved by the Institutional Ethics Committee

\section{REFERENCES}

1. Cheng Y, Xu X, Wuillaume F, Zhu J, Gibson D, Temmerman M. The need for integrating family planning and postabortion care in China. Int $\mathbf{J}$ Gynaecol Obstet. 2008;103(2):140-3.

2. Thawal Y, Deshpande H, Patvekar M, Suryarao P, Bhalani R, Jindal S. Study of acceptance of postabortal contraception in tertiary care centre. Int J Clin Obstetr Gynaecol. 2018;2(5):147-52.

3. Lähteenmäki P. Post-abortal contraception. Ann med. 1993;25(2):185-9.

4. Ferreira. Choices on contraceptive methods in postabortion family planning clinic in the northeast Brazil. Reproductive Health. 2010;7:5.

5. Bizuneh AD, Azeze GG. Post-abortion family planning use, method preference, and its determinant factors in Eastern Africa: a systematic review and meta-analysis. Syst Rev. 2021;10:172.

6. Kathpalia SK. Acceptance of family planning methods by induced abortion seekers: An observational study over five years. Med J Armed Forces India. 2016;72(1):8-11.

Cite this article as: Indumathi $\mathrm{HK}$, Patil SB, Radhika, Savitha C, Nayana MS. Study of acceptance of post-abortal contraception in a tertiary care centre. Int J Reprod Contracept Obstet Gynecol 2021;10:3379-82. 